\title{
Attitudes and Preferences of Self-Repair and Corrective Feedback of Oral Production in Classroom: A Corpus-Based Study The case of Second Year LMD students at the University of "Frères Mentouri" Constantine
}

\begin{abstract}
:
Oral errors are commonplace in the EFL learning process. The willingness to elicit teachers' and students' collaboration in error treatment towards enhancing oral production and uptake is the aim behind this study. Based on the main questions "Who, when, what and how to correct?" and "How much uptake is generated?", two attitudinal questionnaires were delivered to 150 second year LMD students and 16 teachers in the English department inquiring their perceptions about error repair. We further probed both teachers' and students' repair behaviour via a non-participatory natural classroom observation during 16 hours of oral courses varied between interaction and presentations. We detected controversial, though not conflicting, results on two levels of analysis: Students' Vs Teachers' attitudes and preferences towards the repair of oral failures, besides the claimed attitudes Vs those revealed during classroom observation which generated average amounts of students' uptake. These findings lend a strong support for our hypothesis, which speculates that the betterment of students' spoken language can be achieved through a conscious cooperation between teachers and students regarding each others' preferences towards error treatment. Those preferences are worthy of further pursuit of research
\end{abstract}

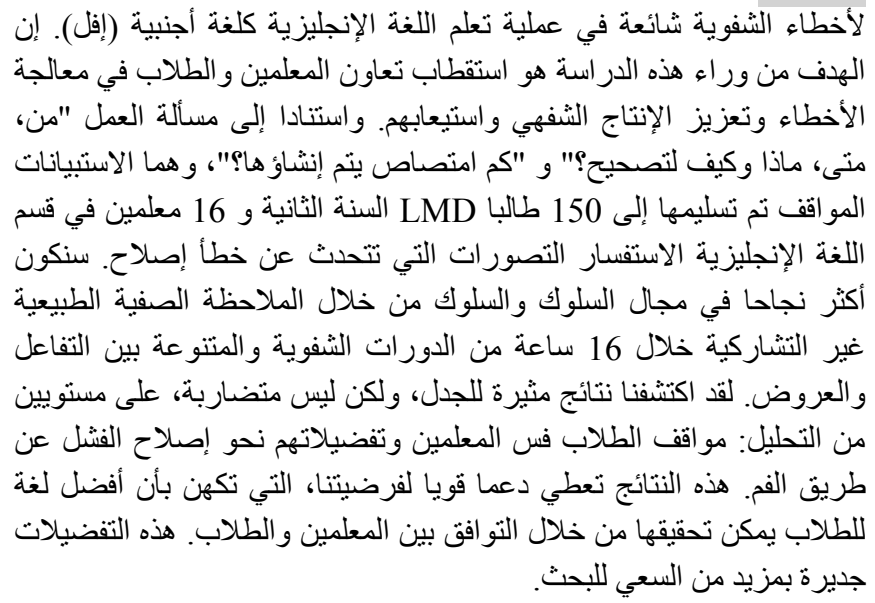

\section{Fahima AOUICHE}

Faculty of Letters and Languages

Department of Foreign Languages

University of Mentouri

Constantine

\section{Introduction :}

After almost 40 years, research in the domain of error treatment is still paralleled with the Hendrickson's frame (1978) about corrective feedback on learners' oral breakdowns: Should learners' errors be corrected? Who should do the correcting? When should learners be corrected? Which error types should be corrected? How should errors be corrected? 
These questions are investigated in our study with regard to the intensity of both self-repair (SR) and corrective feedback (CF) in EFL classes in the English Department, University of Constantine1; moreover, the amounts of uptake attained are measured beneficial to identifying the combinations of $\mathrm{CF}$ techniques effective in generating higher extents of uptake. As such, we endeavour the strengthening of what we hypothesized as the inevitable contribution a "teacher-student alliance" can afford in the enhancement of the latter's spoken language through error correction.

\section{1- Error and Correction}

Controversies about error correction have been raised among researchers and EFL teachers for two reasons; the divergence of attitudes towards error and its repair among students' and their teachers, which generated a complexity of the error treatment process itself, and the debate addressed by the eminent question: Do students attain certain language proficiency from error treatment?.

An error is defined to be the deviation from the target language norms (Allwright and Baily, 1991. Cited in Taipal, 2012) which imposes a questionable sense akin to the English language diversity on the one hand, and the fact that it is being taught by non-native speakers as a foreign language all over the world, on the other hand; as such, the concept "norm" would be hardly followed. Corder (1967) defined errors as the reflection of learners' actual inter-language phase, resulting in breakdowns in speech which are, according to James (1998. Cited in Taipal, 2012), considered to be deviant outputs because of their grammaticality or acceptability reasons(Previously stated to be complementary to competence and performance, in the same order, in Chomsky's work, 1965); in which the first notion decides upon the correctness of syntactic, phonological and even semantic aspects of the spoken utterance, whilst the second is associated with the communicability of that utterance in specific linguistic contexts.

A distinction between an error and a mistake has to be established as well. Corder (1967) considered errors the results of the learner's poor linguistic competence, while mistakes are manifested in the speaker's performance as merely slips of the tongue or memory failures which generally characterize native speakers' production as well as EFL learners; as such unlike natives who roughly owe the complete linguistic knowledge about the language to overcome mistakes, non-native learners need a back-up from other interlocutors to repair their spoken mismanagement. Therefore, we opt for a definition of error that bears the interference of the teacher in repair works by authorizing corrective feedback (Cited in Lee, 1990).

An objective evaluation of linguistic or content errors according to linguistic norms or evident misconstrual of fact, and any additional linguistic or other 
behaviour that the teachers reacted to negatively or with an indication that improvement of the response was expected. (Chaudron 1986: 67)

Error may be categorized along a number of dimensions. On a linguistic level, we recognize four major types of error: Grammatical, Discourse, phonological errors and lexical errors. However, regarding the error gravity, it is relatively complicated to decide the extent of gravity for the simplest reason that the seriousness of a spoken error depends on a variety of variables like age and the academic discipline (Lee, 1990). Researchers recognised four categories associated to this dimension: As regard to errors linked to intelligibility. In 1972, Burt and Kiparsky (ibid) classified errors into global, which affect the communicability of the message and local errors affecting the syntax of the spoken utterance which intermittently have certain impact on communication as well. Other error types acknowledged by researchers and practitioners were classified under the same dimension of gravity, labelled as irritating (Ludwig, 1982), common (Holey and King, 1971) and high frequency errors (Allwright, 1975) are of less interest in our study.

Practically, all errors can be corrected; their correctibility, however, is limited by terms of when, how and by whom repair is done, and which errors are processed; besides the proficiency echo repair work reflects on learning. Depending on which approach one can adopt, he or she will find error correction described on a continuum ranging from ineffectiveand possibly harmful (e.g., Truscott, 1999. Cited in Lyster, 2001) tobeneficial (e.g., Lyster \& Ranta, 1997; Lyster, 2001; Ellis, 2013; Russell \& Spada, 2006). The most critical question, however, is whether repair is done by the learner who produced the error or the teacher as the most proficient participant in classroom conversation, or even by both.

\section{2- Self Repair(SR)}

According to van Hest (1998b): "If the speakers' monitoring device meets with a troublesome item, speakers can decide to correct this item on their own initiative, without intervention from their interlocutors" (Cited in Wang,2003). These types of repairs are called self-repairs $\boldsymbol{S R}$. From the psycholinguistic perspective, a self-initiated self-completed repair has consequential benefits on the learners' interlanguage system: Having its confirmation from laboratory studies (Schegloff, Jeffersson \& Sacks, 1977), the impact of self initiated repairs correlated positively with successful completions, and therefore improved future performance. As such it is plausibly valuable that teachers are advised to authorize such conversational opportunities for students because self corrections and interjections they make while talking show that self-monitoring is underway, and are usually for the purposes of making meaning clearer. 
Techniques utilized by learners to personally endeavour their spoken failures vary in accordance with their competence level. The most common classification to learners' strategies of self repair was adapted by Schegloff et.al. ( 1977) in which the learner who produced the trouble source self initiates repair work with a partial or a full repetition of the occurred error, ensuring time- conservation by non lexical initiators; those of which are represented by cut-offs, quasi-lexical fillers and lengthening of sounds.Then s/he completes with an insertion of the correct target-like form. Repetition is stated to be the most commonly used technique and conceivably the most profitable for students in other research (Rahimi\& Dastjerdi, 2012).

Learners' contribution in repair work/ error treatment is not defined merely by self-initiated self-completed repair(S.I.S.R)as labelled by Hall (2007), but with three other types regarding the other participants' interference in the process namely self-initiation other-repair (S.I.O.R), other-initiation selfrepair (O.I.S.R) and finally, not containing the trouble source participation, the other-initiation other completion repair (O.I.O.R).

\section{3- Corrective Feedback (CF)}

Support provided by teachers to overcome the spoken failures is called corrective feedback $\boldsymbol{C F}$. It has been established that $\mathrm{CF}$ is respectively beneficial to adjust learners' hypotheses about the language: Between 2006 and 2010, four valuable meta-analyses of CF research conducted by Russell and Spada in 2006; Mackey and Goo in 2007; Li in 2010; Lyster and Saito in 2010 (Cited in Lyster, Saito \& Sato, 2013) described it to have substantial effectiveness in fulfilling the aims behind error correction.

Lyster and Ranta were known for their most comprehensive studies about $\mathrm{CF}$ and its types in French immersion classrooms in 1997 and later in 2007.They categorized teachers' corrective behaviour into 6 major types, ranging from the most implicit to the extensively explicit according to Sheen and Ellis (2011:594).These types are: reformulations, which represent Recasts and explicit corrections. In addition to prompts which indicate the troubled output in the students' speech without authorizing the correct target-like reformulation as the first type allows for; this type involves the use of elicitations, metalinguistic clues, clarification requests and repetitions.

The choice of what type of error to be targeted by CF and even when to administer it depends thoroughly on the teachers' approach besides the current classroom activity: If the teacher is involving in a content-based instruction activity, then it is preferable to avoid what Sheen (2004) labelled as negative evidence (Cited in Lyster et.al., 2013) addressing grammatical and phonological inaccuracy; furthermore, a delayed correction would be of more efficacy in preserving the communication flow. When the teacher applies for form-based instruction though, the non-target outputs to be dealt with are those having an impact on accuracy rather than fluency, and both immediate or 


\section{Attitudes and Preferences of Self-Repair and Corrective Feedback \\ of Oral Production in Classroom: A Corpus-Based Study The case of Second Year LMD students at the University of "Frères Mentouri" Constantine}

delayed CF would be of vital contribution in attaining the trouble source' attention towards his error (Méndez\& Cruz, 2012).

\section{4- Uptake and Effectiveness of Corrective Feedback Types}

The term uptake has been defined in at least two different ways in SLA literature. Previously in some studies, it referred to something that learners themselves can report to have learnt from a particular lesson (Allwright 1984.Cited in Taipal, 2012). Nowadays, in corrective feedback studies it implies the learner's response to the teacher's feedback. Lyster and Ranta (1997) defined uptake as "a student's utterance that immediately follows the teacher's feedback and that constitutes a reaction in some way to the teacher's intention to draw attention to some aspect of the student's initial utterance" ( $\mathrm{p}$. 46).

Successful uptake or 'utterances with repair', opposed to "utterances still in need for repair" (Lyster and Ranta, 1997), can facilitate acquisition for at least two reasons. First, uptake supplies learners with opportunities for testing their own hypotheses about the already acquired items of the language; subsequently they automatize the production of reformulated output, which prompts the development of connections in memory. Second, Swain (1985, Cited in Faqeih, 2012) claims that "Comprehensible input" alone is insufficient without "pushed output" to achieve target-like accuracy and fluency. Uptake, therefore, has the potential to trigger acquisition though it is not an instance of acquisition itself.

Researchers and instructors as well encountered a consistent controversy about which type of $\mathrm{CF}$ has intense effectiveness on learners' language proficiency, especially when it comes to deciding between recasts and prompts. They roughly concluded, yet, that no CF type has superiority over another (eg; McDonough, 2005); learners are likely to gain equal enhancement from all types of CF if utilized comprehensively and continuously with regard to the classroom context and the aimed language attribute (Lyster et.al., 2013).

\section{Database}

Data collection in the current research was arranged in a process of exploring teachers' and students' inclinations about error treatment in the English Department, University of Constantine. This was achieved via two attitudinal questionnaires, and then the validity of findings was checked throughout a naturalistic observation of the participants' repair behaviour during classroom interaction.

\section{1- Students' and Teachers' Questionnaires}

We administered a questionnaire to 150 second year LMD students of EFL who were randomly selected out of 700 students enrolled in the English 
department at Constantine university1, during the academic year 2014-2015; we further opted for a similar questionnaire to be filled by 16 EFL teachers in the same department who had been teaching different modules for a considerable time (14 of them had been teaching Oral Expression, 5 of whom for more than 5 years). The two attitudinal questionnaires were designed to probe the participants' attitudes and preferences towards error treatment on the one hand, and towards each others' preferences on the other hand; questions of the research: who, when, what and how to correct were addressed in separate sections of both questionnaires. Nonetheless, the teachers' questionnaire included extra investigation about the students' proficiency and involvement in error correction levels besides an inquiry of the speculated uptake attained from each CF type.

\section{2- Classroom Observation}

The second method of data collection in the present study was qualitative emic in which emic is the concept of being part of the system when inquiring a social phenomenon (Pike, 1967). The authenticity of data was preserved as we did not interfere during interaction.

\subsection{Observation Procedure and Setting}

A 16 hours' natural observation was conducted to examine the corrective behaviour of both teachers and students in an authentic setting. The recorded Oral Expression courses varied between presentations, interaction and listening-speaking sessions.

\subsection{Analysis Procedure of the Classroom Observation}

It is noteworthy to state that regarding time limitations and the repeated pattern of findings, we opted for the analysis of merely 4 classroom sessions, one of which is being presented as an exemplar in this article. The procedure of analysis depended on classifying students' errors into 4 major categories: Grammatical, phonological, lexical errors and intelligibility breakdowns; as such we could deduce which error type was likely to be corrected. Furthermore, we extracted the extents of contribution in error treatment via applying Hall categories of repair (2007), in which S.I.S.R represented students' complete self repair, while O.I.S.R and respectively $\boldsymbol{O} . I . O . R$ were the echo for teachers' support in repair works; the latter repair category involves peers' interference as well. Subsequently, we deployed Schegloff et.al model of self repair strategies (1977) to explore students actual aptitudes when autonomously endeavour their spoken failures, while we applied Lyster and Ranta taxonomy (1997) to decode teachers' intervention moves inserting the addition brought by Sheen and Ellis (2011) as regard to explicit correction with metalinguistic explanation. We finally measuredthe number of successful andpartial uptake moves (labelled as utterances with repair and utterances still in need for repair by Lyster and Ranta). 
Results

The findings revealed some discrepancies between what was claimed by informants in both questionnaires and what the classroom observation disclosed. The inquiry questions were respectively answered in relation to the data from the three research tools.

\section{1- Should students' spoken errors be corrected?}

Both attitudinal questionnaires and the classroom observation revealed an approval about the inevitability of error correction. The optimal majority of teachers $\mathbf{( 9 3 . 5 \% )}$ confirmed that their students' oral failures ought to be handled; students as well reported a high perseverance towards correcting their errors with merely $\mathbf{1 8 \%}$ admitting they ignore correction. The natural observation also exposed a relatively elevated focus on error treatment: Out of 230 errors made during the session, 154 repair works (66.95\%) were delivered by all participants in interaction.

\section{2- Who corrects?}

Identifying the participant who devotes more attention and effort to engage in error correction showed some discrepancies in findings: Teachers, with a proportion of $87.5 \%$, asserted they afford treatment via corrective feedback (CF) more than any other participant, whilst they claimed very low percentages of contribution afforded by students via self repair (SR), $12.5 \%$, and they acknowledged lower participation of peers in correction (6.25\%). Students, on the other hand, confirmed that their spoken troubles are mostly solved by $\mathrm{CF}$ as reported by $61 \%$ of them, $52.66 \%$ though claimed they apply for SR as well. The classroom observation detected a confirmation of the prior claims with a slight difference between the actual SR and CF moves; the latter was spotted by $41.55 \%$, whereas SR attempts scored $43.5 \%$. The following graph illustrates the data. 


\section{Fahima AOUICHE}

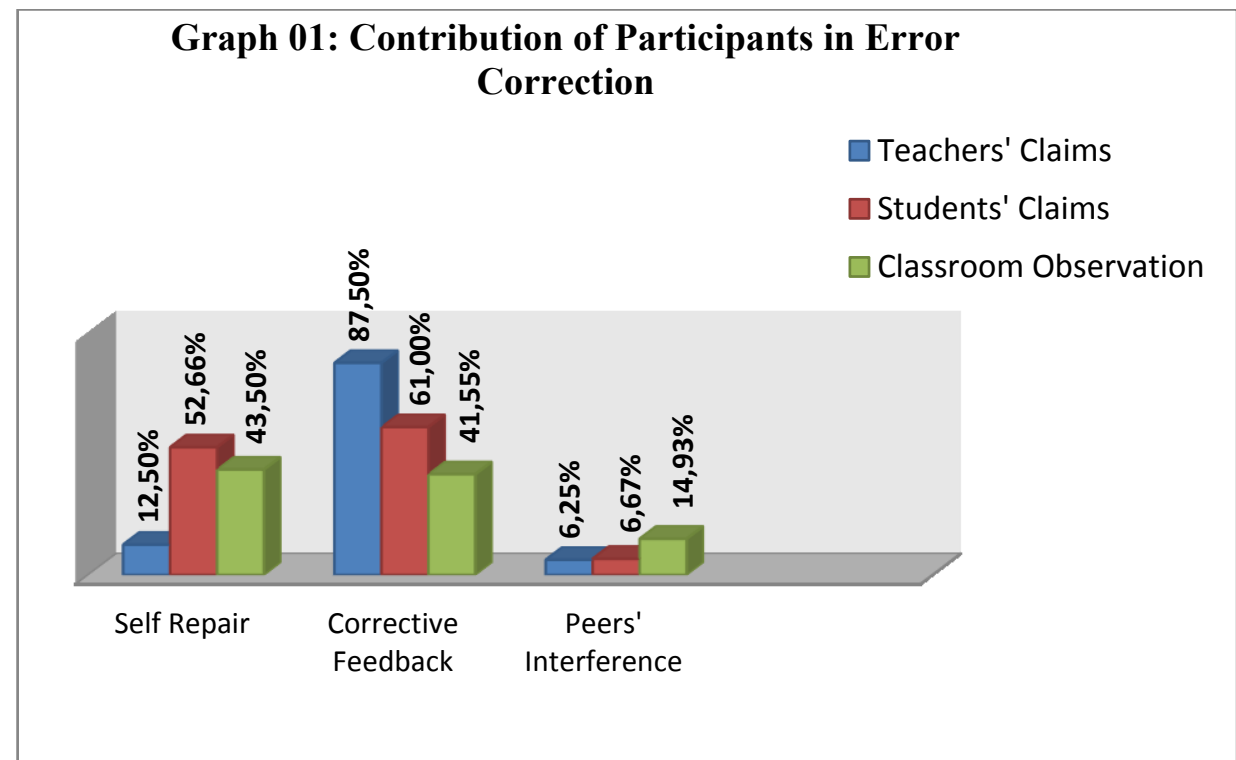

3- When to Provide Corrective Feedback?

Findings about the appropriate timing for authorizing CF disclosed another controversy between the teachers and their students; as such, teachers declared they prefer delayed and postponed $\boldsymbol{C F}$ with a substantial percentage of $\mathbf{7 5 \%}$, students also reported a slightly higher preference towards delayed rather than immediate CF, $54.66 \%$ against $42 \%(6.25 \%$ of teachers and $3.33 \%$ of students showed neutral responses). Corrective feedback however was detected to be rather immediate during classroom observation; 76.56\% of CF moves were instantly provided by teachers. 
Attitudes and Preferences of Self-Repair and Corrective Feedback

of Oral Production in Classroom: A Corpus-Based Study The case of Second Year LMD students at the University of "Frères

Mentouri" Constantine

\section{Graph02: Immediate and Delayed/Postponed CF}

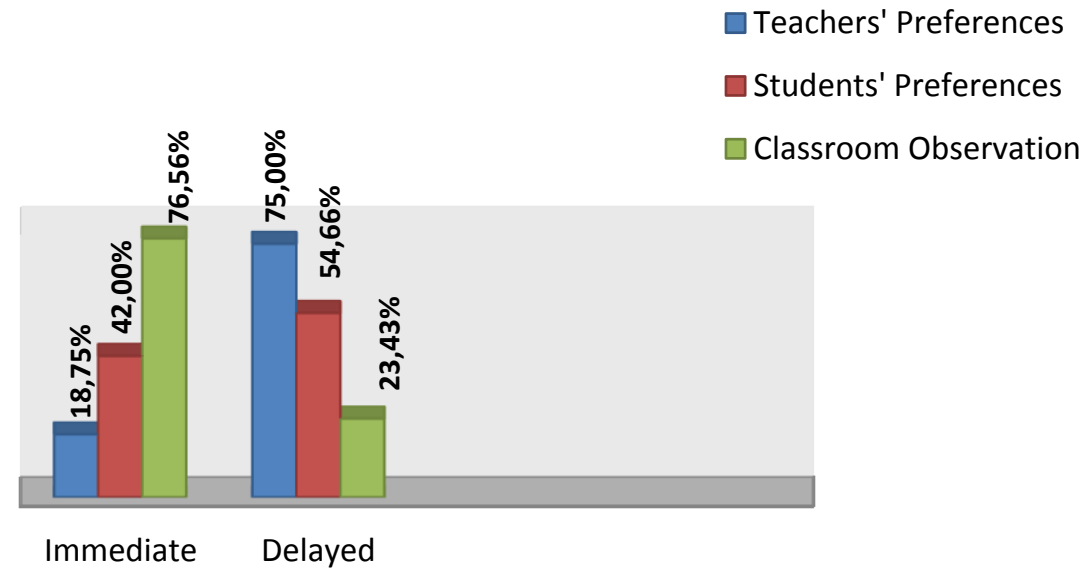

4- Which error types to be corrected?

The types of errors that should be corrected received controversial preferences amongst the teachers and their students even when compared to the actual attitudes revealed during the observation. While teachers acknowledged a convention to endeavour spoken errors causing unintelligibility $(\mathbf{9 3 . 7 5 \%})$ more than any other type, opposed to the effort directed to grammatical errors $(25 \%)$, students exposed a tendency to pay relatively more attention to inaccurate grammar or phonology errors( $65.66 \%$ and $75.33 \%)$. Teachers' perception was well mirrored in the selection of error types that were corrected the most during the observation: $\mathbf{9 7 . 2 9 \%}$ linked to intelligibility failures were corrected, whereas the least amount of treatment, $41.39 \%$, was spotted in the correction of inaccurate outputs. 


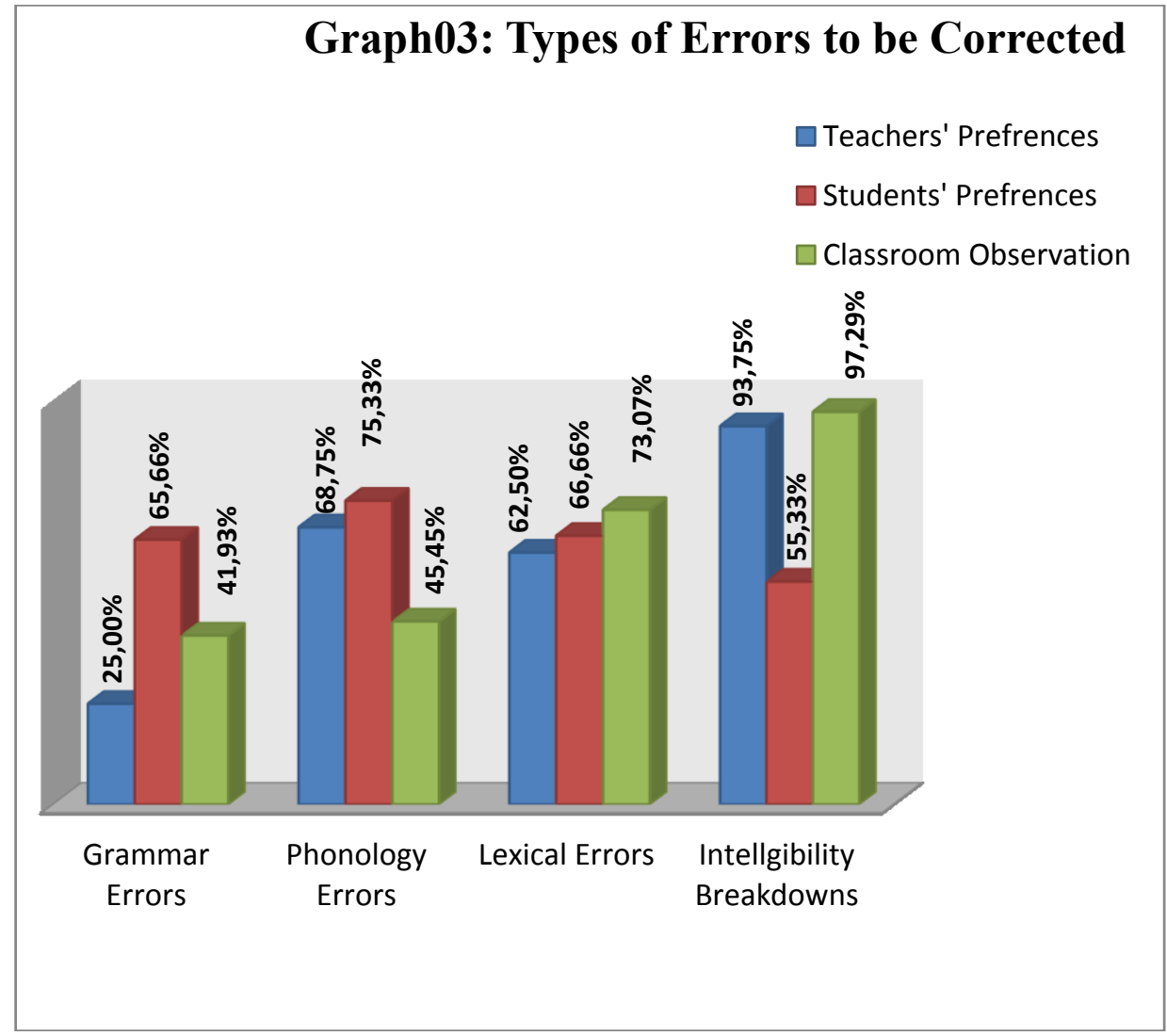

\section{5- How to correct?}

5.1- Corrective Feedback

As regard to Lyster and Ranta taxonomy (1997), preferences towards techniques deployed in authorizing CF by the teacher had the most conspicuous discrepancies in our research; these were reflected in the distinction between teachers' eagerness to utilize prompts, especially repetitions $(93.75 \%)$ and elicitations (87.5\%), and students' inclination towardsreformulations presented mainly by recasts (72\%) and explicitcorrectionwithmetalinguisicexplanation (67.32). Nevertheless, the classroom observation conceded an overwhelming application of recasts, $57.81 \%$, followed by elicitation, $29.68 \%$, then clarification requests, explicit correction and a combination of both recasts and elicitation with very low percentages. The noteworthy finding was the absence of repetition which was thoroughly claimed by teachers to be extensively used. 
Attitudes and Preferences of Self-Repair and Corrective Feedback of Oral Production in Classroom: A Corpus-Based Study The case of Second Year LMD students at the University of "Frères Mentouri" Constantine

\begin{tabular}{|l|l|l|l|}
\hline CF Types & $\begin{array}{l}\text { Teachers' } \\
\text { Preferences }\end{array}$ & $\begin{array}{l}\text { Students' } \\
\text { Preferences }\end{array}$ & $\begin{array}{l}\text { Observation } \\
\text { Findings }\end{array}$ \\
\hline $\begin{array}{l}\text { Clarification } \\
\text { Requests }\end{array}$ & $62.5 \%$ & $63.99 \%$ & $6.25 \%$ \\
\hline Repetitions & $\mathbf{9 3 . 7 5 \%}$ & $30 \%$ & $0 \%$ \\
\hline Recasts & $75 \%$ & $72 \%$ & $\mathbf{5 7 . 8 1 \%}$ \\
\hline Elicitations & $87.5 \%$ & $61.32 \%$ & $29.68 \%$ \\
\hline Metalinguistic Clues & $50 \%$ & $46 \%$ & $0 \%$ \\
\hline Explicit Corrections & $31.25 \%$ & $32 \%$ & 4.68 \\
\hline $\begin{array}{l}\text { Explicit Correction } \\
\text { + Explanation }\end{array}$ & $50 \%$ & $67.32 \%$ & $0 \%$ \\
\hline Other combinations & $0 \%$ & $0 \%$ & $1.56 \%$ \\
\hline
\end{tabular}

Table 01: CF Preferences between Claims and Observed Attitudes

Note: The sums of percentages in the table are not $100 \%$ for both teachers' and students' preferences because participants showed relative convention towards different types in the same time.

5.2- Self Repair Strategies

We detected an agreement amongst teachers $(81.25 \%)$ that students utilize repetitions of their spoken lapses; nonetheless, students themselves disclosed an aptitude to use direct paraphrasing/ substitution instead of repetition with an approval of $53.33 \%$. The classroom observation confirmed students' impulse to fulfil SR via a divergence of repetitioncombinations consisting mainly of "Non-lexical initiators + Full/ Partialrepetition+ insertion" $\mathbf{( 4 0 . 2 9 \% )}$ ) and then there were other combinations as shown in table 02 . 


\begin{tabular}{|c|c|c|}
\hline \multicolumn{3}{|c|}{ Graph 04: The Use of Repetition and Paraphrasing in SR } \\
\hline 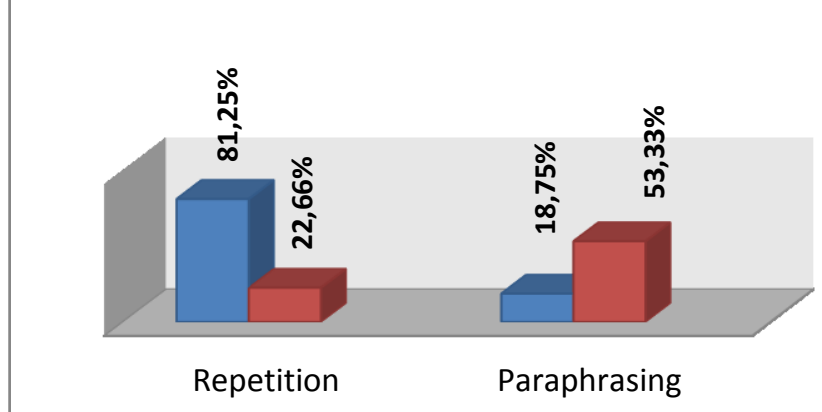 & $\begin{array}{l}\square \mathrm{Te} \\
\square \mathrm{St}\end{array}$ & $\begin{array}{l}\text { hers' Claims } \\
\text { lents' Claims }\end{array}$ \\
\hline Strategies & Number & $\%$ \\
\hline $\begin{array}{l}\text { Non-lexical Initiators }+ \\
\text { Full/Partial)+insertion }\end{array}$ & 27 & $40.29 \%$ \\
\hline $\begin{array}{l}\text { Non-lexical Initiators+ repetition( Full/Partial)+ } \\
\text { substitution }\end{array}$ & 01 & $1.49 \%$ \\
\hline Non-Lexical Initiators+ Insertion & 01 & $1.49 \%$ \\
\hline Non-lexical Initiators+ Substitution & 06 & $8.95 \%$ \\
\hline Repetition( Full/Partial)+Insertion & 08 & $11.94 \%$ \\
\hline Repetition( Full/Partial)+Substitution & 15 & $22.38 \%$ \\
\hline Insertion & 01 & $1.49 \%$ \\
\hline Substitution & 04 & $5.95 \%$ \\
\hline Partial Repetition+ Substitution+ Insertion & 01 & $1.49 \%$ \\
\hline Non- verbal resources & 03 & $4.47 \%$ \\
\hline Total & 67 SR & $99.95 \%$ \\
\hline
\end{tabular}

Table02: Self Repair Strategies Revealed in Classroom Observation

6- Which Corrective Feedback Generates Higher Uptake?

Opposed to what teachers believed, as stated in the teachers' questionnaire , the classroom observation disclosed a vital role of recasts in stimulating an intense uptake, either successful or partial, with a proportion of $19(52.77 \%)$ out of 36 uptakes scored during repair works RW led by the teacher(64 repair works). This was followed by elicitations, $33.33 \%$, which were asserted by teachers to be equally in the first position with repetitions in promoting uptake through the agreement of $31.25 \%$. (Uptakes generated by peers' interference scored 10 out of $23 \mathrm{RW}$ ).

\begin{tabular}{|l|l|ll|}
\hline CF Types & Uptake as claimed by & Uptake in \\
\hline
\end{tabular}


Attitudes and Preferences of Self-Repair and Corrective Feedback

of Oral Production in Classroom: A Corpus-Based Study The case of Second Year LMD students at the University of "Frères Mentouri" Constantine

\begin{tabular}{|l|l|l|}
\hline & Teachers & Observation \\
\hline Clarification Requests & $0 \%$ & $8.33 \%$ \\
\hline Repetition & $31.25 \%$ & $0 \%$ \\
\hline Recast & $12.5 \%$ & $\mathbf{5 2 . 7 7 \%}$ \\
\hline Elicitation & $31.25 \%$ & $33.33 \%$ \\
\hline Metalinguistic Clues & $6.25 \%$ & $0 \%$ \\
\hline Explicit Correction & $0 \%$ & $0 \%$ \\
\hline $\begin{array}{l}\text { Explicit Correction+ } \\
\text { Explanation }\end{array}$ & 6.25 & $0 \%$ \\
\hline Recast+ Elicitation & $0 \%$ & $5.55 \%$ \\
\hline All of them & $12.5 \%$ & $0 \%$ \\
\hline Total & $100 \%$ & $100 \%$ \\
\hline
\end{tabular}

Table03: Extents of Uptake Generated by CF Types Interpretations of the Results

Findings suggest that teachers and students in the English Department, University of Constantine, have an extensive perseverance towards the essentiality of error correction. The rationale behind this positive attitude, having its echo in the elevated amounts of repair works (66.95\%), is akin to a variety of reasons; one of these is that many students expect their errors to be corrected and can feel frustrated if they are ignored. The second reason is the danger of disregarding the non-target like outputs, which might serve as an input model to be acquired by other students in the class. Thirdly, taking part in corrective feedback can speed up the learning process (Lyster \& Ranta, 1997, Lyster2001, Russell \& Spada, 2006) through utilizing the conversational and the linguistic modifications in testing information about the rules and the limits of language use, which would otherwise take students a long time to deduce on their own. The same perception explains why both teachers and students revealed an inclination to authorize/accept CF over SR (See graph 01) regarding the teacher as the proficient participant while processing an error. Furthermore, the nearly equal amounts of SR and CF observed in the classroom assert that both participants devote appreciable efforts to solve speech problems. An annotation to be discussed here is the teachers' claims of the very low contribution of students via SR $(12.5 \%)$, which was respectively opposed by students' actual repair behaviour ( $43.5 \% \mathrm{SR})$; this can be associated with a two-fold interpretation: The average extents of SR reflect students' awareness and willingness to self monitor their speech via testing their own hypotheses about the language, which is critical to amplify oral proficiency (Schegloff et.al., 1977). The other explanation, vibrant and equally persuasive, is that the efforts that students are adding to their learning process are higher than their 
teachers' expectations; this might inhibit the collaboration between the two participants to benefit from error correction itself.

The serious gap detected between students' eagerness for more immediate $\boldsymbol{C F}$ and teachers' claimed preferences for delayed $\boldsymbol{C F}$ (75\%) was reduced to fit students' desire according to the classroom observation findings $(76.56 \%$ of $\mathrm{CF}$ was delivered instantly); speculations about this refer to the teachers' awareness that immediate $\mathrm{CF}$ withholds the flow of communication and detains fluency. They attempted, however, to adapt their CF with the students' needs, which subsequently expanded successful uptake confirming the effectiveness of immediate over delayed CF (Barbetta, Heward, Bradely \& Miller, 1994) on the one hand, and affording evidence to our hypothesis that gave importance to consider students' preferences.

The debate about prompting accuracy or fluency still has its impact on educators and EFL teachers. The accurate findings of dignifying communicative failures' treatment based on both teachers' preferences (93.75\%) and the actual attitudes in the observation (97.29\%), against the least amounts of correction aimed at Grammar errors $(25 \%$ and $41.93 \%$ in the same order) indicate the teachers' inclination to rather trigger fluency relying on the fact that over correcting inaccurate output might well impede communication. Furthermore, the interactional nature of the observed session withdrew handling grammatical errors and stimulated conversational repair works, as regard to this perception, there was a dubious neglect of students' extensive demand $(65.66 \%)$ of treatment over their inaccurate language, generating a probable misapprehension in attaining the fundamental collaboration needed in error correction. Moreover, favouring repair of Phonology errors by both teachers and students $(68.75 \%$ and $75.33 \%)$ reflects both participants' desire to reach a native-like accent in students' speech.

Based on the compelling grounds of the effectiveness of prompting $\boldsymbol{C F}$ over reformulations in activating students' awareness of the whole setting of their flawed utterances then eliciting them to draw on their own linguistic resources (Lyster et.al., 2013), EFL teachers at the University of Constantine believed in the amplifications that can be authorized by applying for repetitions and elicitations to generate the maximal extents of uptake; $31.25 \%$ of the sample, which rationalizes the claims of the majority of the teachers about utilizing them the $\operatorname{most}(93.75 \%$ and $87.5 \%)$ against less applicability of recasts $(75 \%)$ regarding the conviction that it stimulates unsatisfactory amounts of uptake according to $12.5 \%$ of them; this is conceivable because recast is recognized to be a mere "echo" (Lyster et.al.,2013)which inhibits, in most cases, the student's attention that an error has been produced in the first place. Nonetheless, teachers were confronted with thoroughly different circumstances during classroom observation: Recasts represented $\mathbf{5 7 . 8 1 \%}$ of repair works, logically delivering the highest degrees of uptake (52.77\%); the perception 
about this might be akin to the permeability and the unobtrusive quality of this type that was asserted in students' attitudes to be entirely appreciated by a proportion of $72 \%$, preferring its direct yet rather implicit nature. Accordingly, teachers were obliged to redirect their corrective behaviour as regard to a complex set of features acknowledging students' preferences.

How to correct errors is not complementary to CF techniques only; in our research we further opted for identifying patterns occurring during students' SR. Schegloff et.al (1977) SR strategies were echoed in students' corrective behaviour, in which repetition of the problematic output with substitution or insertion of the correct item preceded by a recurrent use of non-lexical initiators characterized $73.13 \%$ of SR moves, the same result was previously asserted by $81.25 \%$ of the teachers as an evidence that students tended to repeat their errors to gain extra time for the retrieval of the appropriate target like form.

\section{Conclusion and Implications}

The tentatively interpreted results suggest that teachers and students in the English Department, University of Constantine, are respectively aware of the critical usefulness of error treatment in the enhancement of the students' language proficiency; as such, both participants contribute almost equally in managing spoken breakdowns. Furthermore, despite the discrepancies in preferences towards which type, when and how to correct, the study revealed how critical it is to collaborate not merely during repair works, but rather before setting for error correction itself; teachers should be aware of the spectrum of CF types and their efficacy in generating successful uptake through continuously testing their applicability as regard to students' aptitudes and the fact that error treatment is never One size fits all, besides stimulating students' readiness to respond to $\mathrm{CF}$, not as an alternative to self-repair, but rather as a trigger for intakevianoticingtheinput.

\section{References}

1- Allwright, R.L. 1975. 'Problems in the Study of the Language Teacher's Treatment of Learner Error'. In Burt, M.K. and Dulay, H.C. (eds.), New Directions in Second Language Learning, Teaching and Bilingual Education. Washington, D.C.: TESOL.

2-Barbetta, P.M., Heward, W.L., Bradely, D.M., Miller, A.D. (1994). Effects of Immediate and Delayed Correction on the Acquisition and Maintenance of Sight Words by Students with Developmental Disabilities. Journal of Applied Behavior Analysis. 1994,27, 177-178. 
3-Chaudron, C. (1986). Teachers' priorities in correcting learners' errors in French immersion classes. In R. Day (Ed.), Talking to learn: Conversation in second +language acquisition (pp. 67). Rowley, MA: Newbury House.

4-Chomsky, N. (1965). Aspects of the Theory of Syntax. Cambridge, Massachusetts: MIT Press.

5-Corder, S.P. (1967). The significance of learner's errors. International Review of Applied Linguistics in Language Teaching 5(4): 161-170.

6-Ellis, R. (2013). The Study of Second Language Acquisition. Second edition. Oxford University Press.

7- Faqeih. H.I. (2012). The Effectiveness of Error Correction during Oral Interaction: Experimental Studies with English L2 Learners in The United Kingdom and Saudi Arabia.( Thesis).University of York. Department of Education

8- Hall, J.K. (2007). Redressing the Roles of Correction and Repair in Research on Second and Foreign Language Learning. Modern Language Journal. 91(4). 511-26.

9- Hendrickson, J. (1978). Error correction in foreign language teaching: Recent theory, research, and practice. Modern Language Journal, 62, 387-398.

10- Holley, F.M. and King, J.K. (1971) . 'Imitation and Correction in Foreign Language Learning'. Modern Language Journal 55: 494-498.

11- Lee. N. (1990). Notion of error and Appropriate Corrective Treatment. Hongkong Papers in Linguistics and Language Teaching 13(1990). ISSN 1015-2059

12- Ludwig, J. (1982). 'Native Speaker Judgements of Second Language Learners' Efforts at Communication: A Review'. Modern Language Journal 62: 249-253.

13- Lyster, R. (2001). Negotiation of Form, Recasts, and Explicit Correction in Relation to Error Types and Learners' Repair in Immersion Classrooms. Mc Gill University. Canada. Language Learning Journal, Vol.51.(.265-301). Wiley-Blackwell, Hoboken, NJ, U.S. Retrieved 25 February, 2011 from: http://www.Refdoc.fr/Detailnotice?cpsidt=1162465\& traduire=fr /

14- Lyter, R., Ranta, L.(1997). Corrective Feedback and Learner Uptake "Negotiation of Form in Communicative Classrooms". Cambridge University Press. SSLA 20, 37-66.

15- Lyster, R., Saito, K., and Sato, M. (2013). Oral corrective feedback in second language classrooms.Language Teaching,/ Volume 46 / Issue 01 / January 2013, $\quad$ pp 140 . From http://journals.cambridge.org/abstract S0261444812000365

16- Mendéz, E.H., Cruz, M.R. (2012). Teachers' Perceptions about Oral Corrective Feedback and Their Practice in EFL Classrooms. Bogota, Colombia, /Vol. 14, No. 2, October 2012. ISSN 1657-0790 (printed) 2256-5760 (online), pp 63-75 


\section{Attitudes and Preferences of Self-Repair and Corrective Feedback \\ of Oral Production in Classroom: A Corpus-Based Study The case of Second Year LMD students at the University of "Frères Mentouri" Constantine}

17- McDonough, K. (2005). Identifying the Impact of Negative Feedback and Learners' Responses on ESL Question Development. Cambridge University Press. SSLA, 27, 79-103.

18- Pike, Kenneth Lee (ed.)(1967), Language in Relation to a Unified Theory of Structure of Human Behavior (2nd ed.), The Hague, Netherlands: Mouton 19- Rahimi, A., Vahid Dastjerdi, H. (2012). Impact of Immediate and Delayed Error Correction on EFL Learners' Oral Production: CAF. Mediterranean Journal of Social Sciences, Vol. 3 (1) January 2012,ISSN 2039-2117

20- Russell, J., Spada, N. (2006). The effectiveness of corrective feedback for second language acquisition: A meta-analysis of the research. In J. Norris, \& L. Ortega(Eds.), Synthesizing research on language learning and teaching (pp. 131-164). Amsterdam: Benjamins.

21- Sheen, Y. \& R. Ellis (2011). Corrective feedback in language teaching. In E. Hinkel (ed.), Handbook of research in second language teaching and learning, Vol. 2. New York: Routledge, 593-610

20- Schegloff, E., Jeffersson, G., and Sacks, H. (1977). The Preference for Self-Repair in Organization of Repair in Conversation. Language. 53(ii), (pp: 361-82). Schegloff Publications Archive. From: http://www.sscnet.ucla.edu/soc/faculty/schegloff/pubs/

22- Taipal, P. (2012). Oral Errors, Corrective Feedback and Learner Uptake in an EFL Setting. (Thesis). University of Jyväskylä. From : https://jyx.jyu.fi/dspace/bitstream/handle/123456789/37544/URN NBN fi jyu -201203121409.pdf? sequence $=4$

23- Wang, Z. (2003). A Study on Self-repair Behaviors and EFL Learners' Oral Fluency. (Thesis). School of Foreign Studies,South China Normal University. 